\section{СТАБІЛІЗАТОРИ РОЗВИТКУ ІННОВАЦІЙНОГО ПОТЕНЦІАЛУ ЕКОНОМІЧНИХ СИСТЕМ СФЕРИ ГОСТИННОСТI}

ЛОХМАН Н. В., доктор економічних наук, доцент, зав. кафедри економіки та бізнесу, КОРЕНІЦИНА Т. В., кандидат економічних наук, доцент кафедри економіки та бізнесу, ГРИЩУК О. А., асистент кафедри економіки та бізнесу, Донецький національний університет економіки і торгівлі імені Михайла Туган-

Барановського

\section{STABILIZERS OF DEVELOPMENT OF INNOVATIVE POTENTIAL OF ECONOMIC SYSTEMS OF HOSPITALITY}

\author{
LOKHMAN N., \\ Doctor of Science in Economics, \\ Associate Professor, Head of the \\ Department of Economics and \\ Business, \\ KORENITSINA T. \\ PhD in Economics, Associate \\ Professor of the Department of \\ Economics and Business, \\ GRISCHUK O. \\ Assistant Professor of the \\ Department of Economics and \\ Business, Donetsk National \\ University of Economics and Trade \\ named after Mykhailo Tugan- \\ Baranovsky
}

У статті представлено власний погляд на стабілізатори розвитку інноваційного потенціалу, які представляють собою принципи, які мають забезпечити безперервний, перманентний та ефективний розвиток економічних систем сфери гостинності різних рівнів (країни, регіону, галузі, підприємства). Запропоновано стабілізатори розвитку інноваційного потенціалу сфери гостинності впроваджувати як універсальні принципи: стратегічна спрямованість; системність; динамічність; ефективність; функціональність; реальність, інтегрованість, трансформованість. Визначені принципи мають забезпечити конкурентоспроможність економічних систем сфери гостинності макро-, мезо-, мікро- рівнів.

Ключові слова: інноваційний потенціал, сфера гостинності, принципи, стабілізатори, економічна система, розвиток, рівень.

В статье представлен собственный взгляд на стабилизаторы развития инновационного потенциала, которые представляют собой принципы, обеспечивающие непрерывное, перманентное и эффективное развитие экономических систем сферы гостеприимства на разных уровнях (страны, региона, отрасли, предприятия). Предложено стабилизаторы развития инновационного потенциала сферы гостеприимства использовать в качестве универсальных принципов: стратегическая направленность; системность; динамичность; эффективность; функциональность; реальность, интегрированность, трансформированность. Представленные принципы должны обеспечить конкурентоспособность экономических систем сферы гостеприимства макро-, мезо-, микро- уровней.

Ключевые слова: инновационный потенциал, сфера гостеприимства, принципы, стабилизаторы, экономическая система, развитие, уровень.

The article presents our own view on the stabilizers of innovation potential, which are the principles that should ensure continuous, permanent and effective development of economic systems in the 
hospitality industry at different levels (country, region, industry, enterprise). It is proposed to introduce stabilizers for the development of the innovative potential of the hospitality sector as universal principles: strategic orientation; systematicity; dynamism; efficiency; functionality; reality, integration, transformation. The defined principles should ensure the competitiveness of economic systems in the field of hospitality at the macro, meso and micro levels.

Key words: innovation potential, hospitality sphere, principles, stabilizers, economic system, development, level.

Постановка проблеми. В умовах інтеграції України до світового підприємницького простору виникає необхідність адаптації кожного елементу економічної системи до мінливих змін внутрішнього та зовнішнього середовища через ефективний механізм структурних змін, що можливо забезпечити через розвиток інноваційного потенціалу.

Інноваційний потенціал національної економічної системи на усіх рівнях виступає як сукупні об'єктивні передумови (можливості) цієї системи щодо реалізації ресурсів задля зростання ефективності функціонування на більш якісній інноваційній основі. Сьогодні на перші позиції у побудові економічної системи країни виходить сфера гостинності як найважливіший елемент соціального життя, що відіграє важливу роль у підвищенні ефективності суспільного виробництва та зростанні життєвого рівня населення. Сфера гостинності представляє собою систему взаємопов'язаних напрямів діяльності, до яких відносять забезпечення проживання в готелях, організацію харчування, рекреаційне, транспортне та екскурсійне обслуговування, надання супутніх послуг.

Зважаючи на це, проблема розвитку інноваційного потенціалу сфери гостинності потребує детального дослідження з точки зору формулювання та застосування принципів, як стабілізаторів розвитку інноваційного потенціалу економічних систем різних рівнів.

Аналіз останніх досліджень та публікацій. Питанням розвитку інноваційного потенціалу присвячені праці ряда науковців (Богуславська О. Г. [1], Васильєва Т. А., Лєонов С. В., Кривич Я. М. [2], Гальчук А. А. [3], Денисова О. О., Крисенко О. О. [4], Матвейкин В. Г. та ін. [5], Нуреев Р. М., Симаковський С. А. [6], Омельчак Г. В. [7], Сафаргалієв М.Ф. [9]). В цих публікаціях сформульовано та описано ряд принципів розвитку інноваційного потенціалу, що дає можливість зазначити, що різноманітність цих принципів вимагає постійного їх моніторингу та систематизації на окремих рівнях функціонування економічної системи країни 3 метою забезпечення стабільного розвитку інноваційного потенціалу сфери гостинності як основного фактору підвищення конкурентоспроможності економічної системи.

Метою статті є аналіз та систематизація принципів інноваційного потенціалу сфери гостинності як стабілізаторів його розвитку на макро-, мезо-, мікро- рівнях.

Виклад основного матеріалу дослідження. Логіка дослідження передбачає характеристику інноваційного потенціалу сфери гостинності на рівнях: макро- (рівень економічної системи країни), мезо- (рівень економічної системи регіону та/або галузі), мікро- (рівень економічної системи підприємства).

Макростабілізатори розглядалися такими авторами, як Богуславська О.Г. [1, с. 128], Гальчук А. А. [3], Денисова О. О., Крисенко О.О. [4], Матвейкин В. Г., Дворецкий С. И., Минько Л. В. та 
ін. [5, с. 23]. Так, Богуславська О.Г. [1, с. 128] визначає основний принцип інноваційного потенціалу країни як ефективність інноваційних проєктів. Гальчук А. А. [3] пропонує такі принципи: функціональність, структурність, динамічність. Денисова О. О., Крисенко О. О. [4] надає більш детальну характеристику принципів інноваційного потенціалу: системний підхід в управлінні розвитком інноваційного потенціалу на засадах маркетингу; науковість управління, що передбачає врахування дії економічних законів і закономірностей розвитку; орієнтація управління розвитком інноваційного потенціалу на інноваційний шлях розвитку країни, що сприяє підвищенню конкурентоспроможності шляхом інвестування новацій у нові технології і менеджмент. Матвейкин В.Г., Дворецкий С.И., Минько Л.В. та ін. [5, с. 23], пропонують для інноваційного потенціалу макросистеми наступні принципи: облік загальних закономірностей науково-технічного розвитку світової спільноти; оцінка можливості створінь необхідної науково технологічної бази для проведення прикладних досліджень на проривних наукових напрямках; формування стратегічних пріоритетів інновацінно-технологічного розвитку країни; можливість фінансового забезпечення реалізації всього технологічного ланцюжка створення та реалізації продуктів та послуг; створення умов для того, щоб вихідний фундаментальний науковий потенціал країни мав можливість втілити себе в пріоритетних інноваціях.

Мезостабілізаторами інноваційного потенціалу виступають принципи, представлені автором Нурєєвим Р. М., Симаковскім С. А. [6, с. 41]: необхідність забезпечення кадрової та інвестиційної привабливості інноваційного сектора; визначення пріоритетів інноваційного розвитку регіону в цілому і технологічного розвитку економіки зокрема; комплексне, повне і ефективне використання інструментів розвитку; оцінка ефективності на основі міжнародних стандартів; нівелювання «провалів ринку»; захист і заохочення добросовісної конкуренції в секторі генерації знань.

На нашу думку, більш чіткі принципи представлені в нормативному документі «Регіональні перспективи розвитку технопарків» [8]:

- системний підхід до формування регіональної інноваційної політики;

- створення регіональної інноваційної інфраструктури, що враховує специфіку територій, з наступною інтеграцією в єдину систему;

узгодженість середньострокових пріоритетних напрямів інноваційної діяльності регіонального та загальнодержавного рівнів.

Визначенню мікростабілізаторів інноваційного потенціалу присвячені дослідження таких авторів, як Сафаргалієв М.В. [9, с. 13-14], Омельчак Г.В. [7, с. 115], Васильєва Т. А., Лєонов С. В., Кривич Я. М [2, с. 166-167].

Сафаргалієв М.В. [9, с. 13-14] пропонує наступні принципи: пріоритет інновацій над традиційним виробництвом; забезпечення свободи наукової і науково-технічної творчості; сприяння розвитку конкуренції в сферах науки і техніки; економічність інноваційних процесів; концентрація ресурсів на пріоритетних напрямках розвитку науки і техніки; достатність і обмеженість пріоритетних напрямків; гнучкість інноваційної політики; інтеграція освіти, науки і підприємницької діяльності; сприяння розвитку міжнародного співробітництва. Омельчак Г. В. [7, с. 115] зазначає такі принципи: 
ефективність формування стратегії, необхідність її коригування; стратегічна відповідність можливостей зовнішнього середовища інноваційному потенціалу підприємства; рівень операційної досконалості. На нашу думку, більш детальну характеристику принципів інноваційного потенціалу підприємства представили Васильєва Т.А., Лєонов С. В., Кривич Я. М [2, с. 166-167]: принцип системності; принцип перспективності; принцип прогресивності; принцип співвідношення; принцип реальності; принцип обмеженості та взаємозамінності ресурсів; принцип цільової спрямованості використання інноваційного потенціалу; принцип адаптивності; принцип динамічності; принцип здатності інноваційного потенціалу до розвитку.

На основі розглянутих принципів представляємо власний погляд на стабілізатори розвитку інноваційного потенціалу економічних систем сфери гостинності, які ми пропонуємо розглядати ідентичними для усіх рівнів економічних систем у вигляді структури (рис. 1).

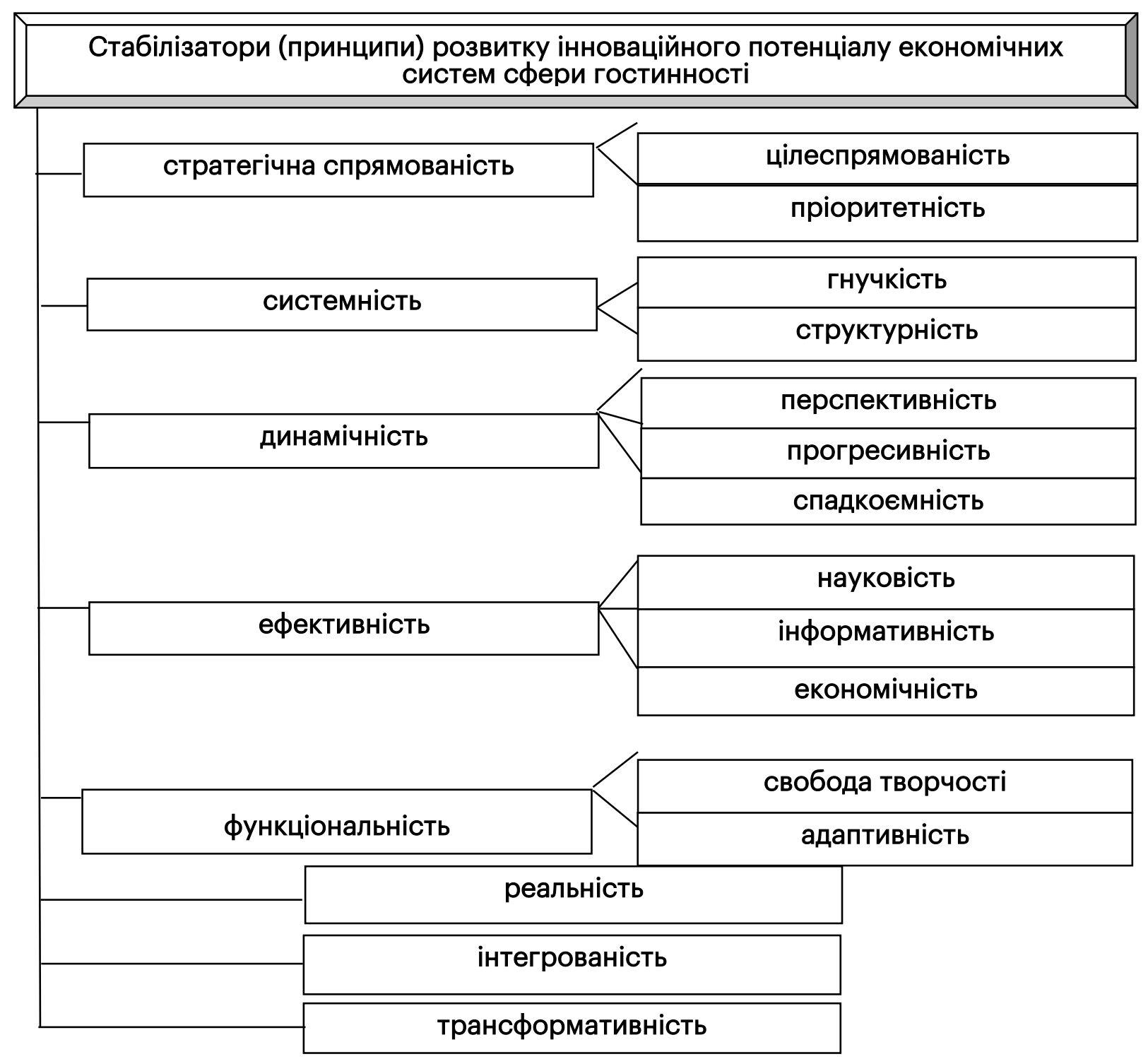

Рис. 1. Стабілізатори розвитку інноваційного потенціалу економічних систем сфери гостинності 
Визначені принципи мають забезпечити безперервний, перманентний та ефективний розвиток економічних систем сфери гостинності різних рівнів (країни, регіону, галузі, підприємства).

Отже, стабілізатори розвитку інноваційного потенціалу сфери гостинності ґрунтуються на універсальних принципах: стратегічна спрямованість (цілеспрямованість, пріоритетність); системність (гнучкість, структурність); динамічність (перспективність, прогресивність, спадкоємність); ефективність (науковість, інформативність, економічність); функціональність (свобода творчості, адаптивність); реальність, інтегрованість, трансформованість.

Висновки і перспективи подальших досліджень. Розглянувши перелік та зміст принципів інноваційного потенціалу макро-, мезо, мікро- рівнів, запропоновано застосовувати загальні універсальні принципи (стратегічна спрямованість, системність, динамічність, ефективність, функціональність, реальність, інтегрованість, трансформованість), які покликані стабілізувати розвиток інноваційного потенціалу сфери гостинності.

Перспективами подальших досліджень $€$ визначення каталізаторів, які мають стимулювати розвиток інноваційного потенціалу економічних систем сфери гостинності на основі визначення його пріоритетів.

Література:

1. Богуславська О.Г. Інноваційна діяльність як фактор забезпечення економічного розвитку. Гуманітарний вісник Запорізької державної інженерної академії. 2008. Вип. 35. С. 127-137.

2. Васильєва Т. А., Лєонов С. В., Кривич Я. М. Концептуальні основи формування системи управління потенціалом інноваційного розвитку підприємства на засадах маркетингу. Маркетинг i менеджмент інновацій. 2011. № 4. Т. І. С. 160-171.

3. Гальчук А.А. Классификация и факторы формирования инновационного потенциала страны. Экономика и Право. 2015. № 910. С. 41-46.

4. Денисова О.О., Крисенко О.О. Інноваційний потенціал підприємства: сутність та структура. Наукове мислення. URL: http://naukam.triada.in.ua/index.php/konferentsiji/38-vosma-

vseukrajinska-praktichno-piznavalna-konferentsiya-naukova-dumkasuchasnosti-i-majbutnogo/100-innovatsijnij-potentsial-pidpriemstvasutnist-ta-struktura.

5. Матвейкин В.Г., Дворецкий С. И., Минько Л. В., Таров В.П., Чайникова Л.Н., Летунова О.И. Инновационный потенциал: современное состояние и перспективы развития: монография. Москва: «Издательство Машиностроение-1», 2007. 284 с.

6. Нуреев Р. М., Симаковский С. А. Инновационный потенциал России в условиях экономических санкций: резервы роста. Вопросы регулирования экономики. 2016. Том 7. № 4. С. 32-47.

7. Омельчак Г.В. Концептуальні основи розвитку інноваційного потенціалу підприємств. Держава та регіони. Серія: Економіка та підприємництво. 2014. № 2 (77). С. 113-118.

8. Регіональні перспективи розвитку технопарків. URL: http://www.raexpert.ru/researches/technopark/part4/. 
9. Сафаргалиев М.Ф. Факторы и принципы освоения инновационного потенциала промышленных предприятий. Вопросы инновационной экономики. 2011. № 10. С. 11-15.

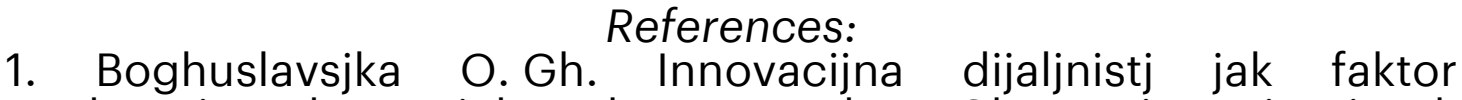
zabezpechennja ekonomichnogho rozvytku. Ghumanitarnyj visnyk Zaporizjkoji derzhavnoji inzhenernoji akademiji. 2008. Vyp. 35. S. 127-137.

2. Vasyljjeva T. A., Ljeonov S. V., Kryvych Ja. M. Konceptualjni osnovy formuvannja systemy upravlinnja potencialom innovacijnogho rozvytku pidpryjemstva na zasadakh marketynghu. Marketyngh i menedzhment innovacij. 2011. \# 4. T. I. S. 160-171.

3. Gal'chuk A. A. Klaccifikatsiya i faktopy fopmipovaniya innovatsionnogo potentsiala ctpany. Ekonomika i Pravo. 2015. № 9-10. S. 41-46.

4. Denysova O. O., Krysenko O.O. Innovacijnyj potencial pidpryjemstva: sutnistj ta struktura. Naukove myslennja. URL: http://naukam.triada.in.ua/index.php/konferentsiji/38-vosma-

vseukrajinska-praktichno-piznavalna-konferentsiya-naukova-dumka-

suchasnosti-i-majbutnogo/100-innovatsijnij-potentsial-pidpriemstva-

sutnist-ta-struktura.

5. Matveykin V. G., Dvoretskiy S. I., Min'ko L. V., Tarov V. P., Chaynikova L. N., Letunova O. I. Innovatsionnyy potentsial: sovremennoe sostoyanie i perspektivy razvitiya: monografiya. Moskva: "Izdatel'stvo Mashinostroenie-1", 2007. 284 s.

6. Nureev R. M., Simakovskiy S. A. Innovatsionnyy potentsial Rossii v usloviyakh ekonomicheskikh sanktsiy: rezervy rosta. Voprosy regulirovaniya ekonomiki. 2016. Tom 7. № 4. S. 32-47.

7. Omeljchak Gh. V. Konceptualjni osnovy rozvytku innovacijnogho potencialu pidpryjemstv. Derzhava ta reghiony. Serija: Ekonomika ta pidpryjemnyctvo. 2014. \# 2 (77). S. 113-118.

8. Reghionaljni perspektyvy rozvytku tekhnoparkiv. URL: http://www.raexpert.ru/researches/technopark/part4/.

9. Safargaliev M. F. Faktory i printsipy osvoeniya innovatsionnogo potentsiala promyshlennykh predpriyatiy. Voprosy innovatsionnoy ekonomiki. 2011. № 10. C. 11-15.

The innovative potential of the national economic system at all levels acts as a cumulative objective prerequisites (opportunities) of this system for the implementation of resources to increase the efficiency of functioning on a better innovation basis.

In view of this, the problem of innovation potential development requires a detailed study in terms of formulation and application of principles as stabilizers of the development of innovation potential of economic systems at different levels.

The logic of the study provides for the characterization of innovation potential at the levels: macro- (level of the economic system of the country), meso- (level of the economic system of the region and / or industry), micro- (level of the economic system of the enterprise).

The following principles apply to the innovative potential of the macrosystem: taking into account the general laws of scientific and 
technological development of the world community; assessment of the possibility of creating the necessary scientific and technological base for conducting applied research in breakthrough scientific areas; formation of strategic priorities of innovation and technological development of the country; the possibility of financial support for the implementation of the entire technological chain of product creation; creating conditions for the initial fundamental scientific potential of the country to be able to embody itself in priority innovations.

The mesostabilizers of innovation potential are the principles: the need to ensure staff and investment attractiveness of the innovation sector; determining the priorities of innovative development of the region in general and technological development of the economy in particular; comprehensive, complete and effective use of development tools; performance evaluation based on international standards; leveling "market failures"; protection and promotion of fair competition in the knowledge generation sector.

More clear principles are presented in the normative document "Regional prospects for the development of technology parks": policy;

- a systematic approach to the formation of regional innovation

- creation of a regional innovation infrastructure, taking into account the specifics of the territories, followed by integration into a single system;

- consistency of medium-term priority areas of innovation at the regional and national levels).

Macrostabilizers include: the priority of innovation over traditional production; ensuring the freedom of scientific and scientific and technical creativity; promoting competition in science and technology; cost-effectiveness of innovation processes; concentration of resources on priority areas of science and technology development; sufficiency and limited priority areas; flexibility of innovation policy; integration of education, science and entrepreneurship; promoting the development of international cooperation. Omelchak GV notes the following principles: the effectiveness of strategy formation, the need to adjust it; strategic compliance of the external environment with the innovation potential of the enterprise; level of operational excellence.

Stabilizers of innovation potential development are based on universal principles: strategic orientation (purposefulness, priority); systematic (flexibility, structure); dynamism (prospects, progressiveness, continuity); efficiency (scientific, informative, costeffective); functionality (freedom of creativity, adaptability); reality, integration, transformation. 